\title{
CONTEÚDO DE MACRONUTRIENTES NA BIOMASSA DE Acacia mearnsii De Wild
}

\section{Macronutrients Content in Biomass of Acacia mearnsii De Wild}

\author{
Leonir Rodrigues Barichello ${ }^{1}$ \\ Mauro Valdir Schumacher ${ }^{2}$ \\ Marcos Vinicius Winckler Caldeira ${ }^{3}$
}

\section{Resumo}

O conhecimento sobre o teor, bem como sobre a distribuição dos nutrientes nas árvores, é fundamental para estabelecer estratégias de amostragem com a finalidade de estudar a nutrição, ciclagem e exportação. Nesse sentido, o presente estudo foi realizado em março de $2001 \mathrm{em}$ um povoamento de Acacia mearnsii com 8 anos de idade, localizado no município de Minas do Leão, RS. Depois de avaliadas as características dendrométricas, foram selecionadas e abatidas 21 árvores do povoamento, sendo quantificados a biomassa e os macronutrientes nos componentes: folhas, galhos vivos, galhos mortos, casca do tronco, madeira do tronco e raízes. Para estimar a quantidade de serapilheira e de nutrientes foram coletadas 42 amostras. No entanto, para estimar a biomassa dos diferentes componentes, foram determinados os coeficientes da equação $\ln \mathrm{y}=\mathrm{b}_{0}+\mathrm{b}_{1}{ }^{*} \ln \mathrm{d}$. A produção de biomassa total foi de 132,1 $\mathrm{mg} \mathrm{ha}^{-1}$. Essa biomassa continha um total de 583,2; 18,6; 1.812,8; 458,7; 89,4; 42,3 $\mathrm{kg} \mathrm{ha}^{-1}$ dos macronutrientes $\mathrm{N}, \mathrm{P}, \mathrm{K}, \mathrm{Ca}, \mathrm{Mg}, \mathrm{S}$, respectivamente e 54,61 mg ha-1 de carbono orgânico. A serapilheira acumulada sobre o solo foi de $25,7 \mathrm{Mg} \mathrm{ha}^{-1}$, contendo um total de 472,9; 15,2; 332,5; 269,8; 32,6; 10,2 $\mathrm{kg} \mathrm{ha}^{-1}$ dos macronutrientes N, P, K, Ca, Mg, S, respectivamente e $8,9 \mathrm{mg} \mathrm{ha}^{-1}$ de carbono orgânico.

Palavras-chave: Carbono orgânico; Serapilheira; Componentes das árvores; Acácia-negra.

\section{Abstract}

The knowledge about the content, as well as on the distribution of the nutrients in the trees, is basic to establish strategies of sampling with the purpose to study the nutrition, cycling and exportation. This study was carried out in March 2001 in an 8 years old settlement of Acacia mearnsii De Wild, from AGROSETA S.A, in "Minas do Leão" county. After the evaluation of the dendrometric characteristics, 21 trees were selected and cut, its biomass and macronutrients in the leaves, alive and dead branches, bark wood, stem wood and roots. To estimate the amount of litter and the nutrients, 42 sampling units were collected. To estimate the different components of the biomass, the coefficients of the equation $\ln =\mathrm{b}_{0}+\mathrm{b}_{1}{ }^{*} \ln \mathrm{d}$, were determined. The production of total biomass was of $132.1 \mathrm{mg} \mathrm{ha}^{-1}$. This total biomass contained 583.2; 18.6; 1,812.8; 458.7; 89.4 and $42.3 \mathrm{~kg} \mathrm{ha}^{-1}$ of $\mathrm{N}, \mathrm{P}, \mathrm{K}, \mathrm{Ca}, \mathrm{Mg}$, respectively and $54.61 \mathrm{mg} \mathrm{ha}^{-1}$ of organic carbon. The litter biomass was $257 \mathrm{mg} \mathrm{ha}^{-1}$, containing 472.9; 15.2; 332.5; 269.8; 32.6 and 10.2, $\mathrm{kg} \mathrm{ha}^{-1}$ of N, P, K, Ca, Mg and S, respectively and $8.9 \mathrm{mg} \mathrm{ha}^{-1}$ of organic carbon.

Keywords: Organic carbon; Litter; Components of the trees; Black wattle.

\footnotetext{
Eng. Florestal, M.Sc. Cambará S/A. Rua Osvaldo Kroeff s/n, 95480-000, Cambará do Sul, RS, leonir.barichello@cambarasa.com.br Eng. Florestal, Dr. Prof. Adjunto do Departamento de Ciências Florestais/Universidade Federal de Santa Maria, RS. schuma@ufsm.br 3 Eng. Florestal, Dr. Prof. do Departamento de Eng. Florestal - Centro de Ciências Tecnológicas/FURB - Universidade Regional de Blumenau, Rua São Paulo, 3250 - Câmpus II - Itoupava Seca - 89030-080, Blumenau/SC, caldeira@furb.br. Autor para correspondência.
} 


\section{Introdução}

A utilidade da Acácia-negra para o setor florestal é vasta, pois serve para produção de lenha para energia, madeira, polpa, papel rayon, celulose, aglomerado, carvão, chapas de fibras, parques, cavacos e tanino (SHERRY, 1971).

Em razão do seu rápido crescimento e do seu potencial na melhoria da qualidade do solo, a Acácia-negra tem sido usada no controle da erosão e na melhoria da fertilidade do solo (WAKI citado por KANNEGIESSER, 1990). A utilização dessa espécie na recuperação de solos degradados é em razão da capacidade de fixação de $\mathrm{N}_{2}$ atmosférico, pois microrganismos fixadores de $\mathrm{N}_{2}$ atmosférico, como bactérias do gênero Rhyzobium, que se associam às raízes finas, reduzem o nitrogênio e o tornam disponível às plantas. As estimativas da fixação de $\mathrm{N}_{2}$ atmosférico em Acácia-negra, conforme Auer e Silva (1992), são aproximadamente $200 \mathrm{~kg} \mathrm{ha}^{-1} \mathrm{ano}^{-1}$.

A quantidade de nutrientes de um ecossistema florestal, segundo Schumacher (1995), é o somatório dos nutrientes contidos no solo, na serapilheira, na vegetação de sub-bosque e na biomassa arbórea do povoamento.

O acúmulo de nutrientes na biomassa arbórea varia de elemento para elemento em razão dos níveis de fertilidade do solo, das características nutricionais de cada espécie e da idade da floresta (SCHUMACHER, 1992; CALDEIRA, 1998; 2003).

A concentração de nutrientes nos tecidos vegetais reflete a influência da fertilidade do solo. De forma geral, os elementos de maiores concentrações são N, K e Ca, em torno de 10 a $50 \mathrm{~g} \mathrm{~kg}^{-1}$ da matéria seca. As folhas e os tecidos corticais acumulam a maior parte dos nutrientes. O lenho tem teores relativa- mente baixos, variando de 2 a $10 \mathrm{~g} \mathrm{~kg}^{-1}$ (LARCHER, 1986).

Na biomassa florestal, a distribuição de nutrientes varia ao longo do tempo. Freitas (2000) relata que, na fase juvenil, o processo é mais acelerado, estabilizando-se quando o povoamento atinge a maturidade. $\mathrm{Na}$ fase inicial do crescimento das plantas, a maior parte dos nutrientes está contida nas folhas. À medida que a idade aumenta, o peso seco e o teor de nutrientes variam, ocorrendo uma translocação dos nutrientes dos órgãos senescentes para as regiões de crescimento das árvores (HAAG, 1985). Os galhos, sobretudo os jovens, são importantes compartimentos de armazenamento de nutrientes. Driessche citado por Bellote e Silva (2000) afirma que a concentração de nutrientes nos galhos novos é alta, sendo comparável ao das folhas, indicando uma reserva local de nutrientes a ser utilizada quando da expansão da copa, crescimento de galhos novos e folhas.

Apesar da Acácia-negra ser plantada há mais de 50 anos no sul do Brasil, os estudos sobre teor de macronutrientes são raros. Nesse sentido, o presente estudo, envolvendo um povoamento de Acácia-negra com 8 anos de idade, teve como objetivos determinar o teor e o conteúdo de macronutrientes estocados na biomassa.

\section{Material e métodos}

\section{Caracterização do local de estudo}

O presente trabalho foi realizado em um povoamento de Acacia mearnsii pertencente à Empresa AGROSETA S/A, localizado no município de Minas do Leão, RS (FIGURA 1). O povoamento se localiza na região fisionômica natural do Estado do Rio Grande do Sul denominada Serra do Sudeste. 


\section{FIGURA 1 - Localização do município de Minas do Leão-RS.}

Figure 1 - Localization of the municipal district of "Minas do Leão"-RS.

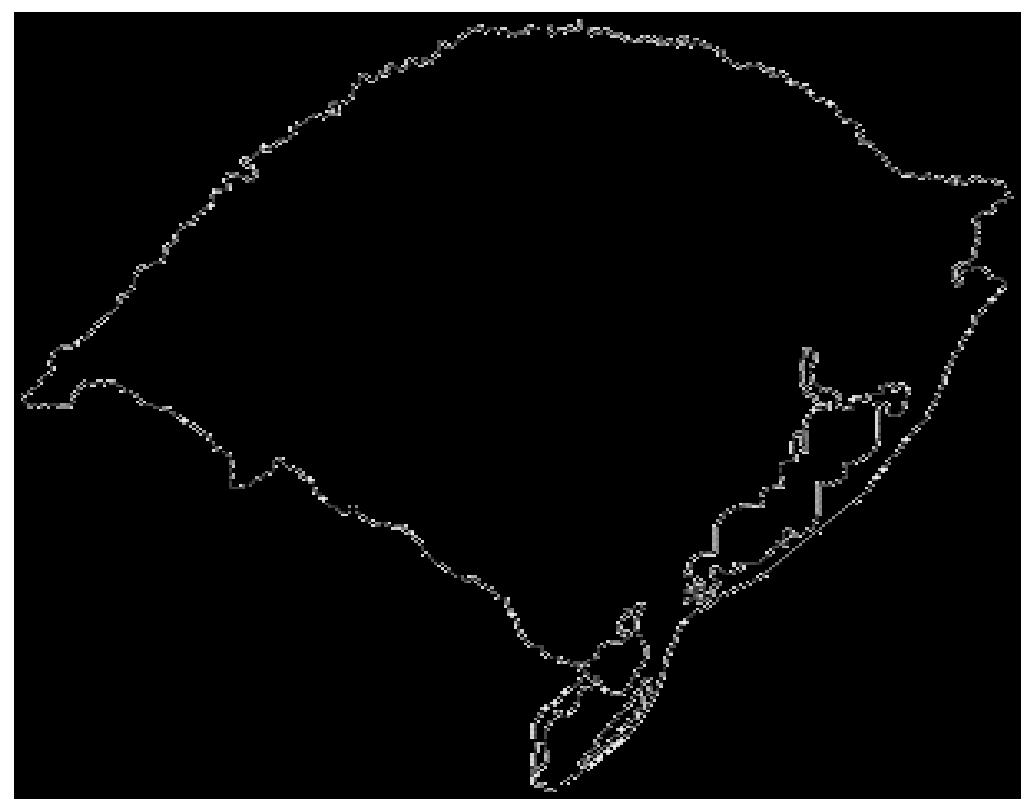

Segundo o sistema de classificação de Koeppen, o clima da região é do tipo Cfa, subtropical (MORENO, 1961). A temperatura média do mês mais quente (janeiro) é de $24^{\circ} \mathrm{C}$, a do mês mais frio (julho) é de $13^{\circ} \mathrm{C}$ e a temperatura média anual é de $18-19^{\circ} \mathrm{C}$. A precipitação pluvial média nos meses de janeiro e julho e a precipitação anual são respectivamente 120-140 mm, $120 \mathrm{~mm}$ e $1400 \mathrm{~mm}$.

De acordo com o INSTITUTO DE PESQUISAS AGRONÔMICAS (1989), a região de Minas do Leão possui, de maio a agosto, 600 horas de frio abaixo de $10^{\circ} \mathrm{C}$ e 200 horas de frio de maio a agosto abaixo de $7^{\circ} \mathrm{C}$. Em relação ao número de dias de chuvas, os meses de janeiro e julho têm, em média, 10 dias chuvosos. Anu- almente, essa região tem, em média, 110 dias de chuva. A umidade relativa do ar, radiação solar e insolação anual são respectivamente 75$80 \%, 350 \mathrm{cal} \mathrm{cm}^{-2} \mathrm{dia}^{-1}$ e 2400 horas.

\section{Metodologia}

Para a caracterização do solo na área experimental (QUADRO 1), foi aberto próximo a cada árvore amostrada uma trincheira de $60 \mathrm{~cm}$ de profundidade. Em cada uma das trincheiras, a cada $20 \mathrm{~cm}$, fez-se uma coleta para determinação da densidade do solo, seguida de uma coleta de solo para análise edáfica. 
QUADRO 1 - Valores médios da análise do solo no local de plantio de Acacia mearnsii. Chart 1 - Soil analysis average values in the site of Acacia mearnsii.

\begin{tabular}{|c|c|c|c|c|}
\hline & \multirow{2}{*}{ Unidades } & \multicolumn{3}{|c|}{ Profundidade $(\mathrm{cm})$} \\
\hline & & $0-20$ & $21-40$ & $41-60$ \\
\hline Densidade do solo & $\mathrm{g} \mathrm{cm}^{-3}$ & 1,42 & 1,44 & 1,39 \\
\hline Argila & $\mathrm{kg}^{-1}$ & 240 & 350 & 410 \\
\hline Matéria Orgânica & g Kg & 23 & 21 & 14 \\
\hline $\mathrm{pH}\left(\mathrm{H}_{2} \mathrm{O}\right)$ & - & 4,1 & 4,2 & 4,3 \\
\hline Nitrogênio total & & 1,31 & 1,03 & 0,75 \\
\hline Fósforo assimilável & $\mathrm{g} \mathrm{kg}^{-1}$ & 8,5 & 3,9 & 2,2 \\
\hline Potássio trocável & & 120 & 137 & 91 \\
\hline Cálcio trocável & & 0,9 & 0,6 & 0,4 \\
\hline Magnésio trocável & & 0,4 & 0,3 & 0,3 \\
\hline Alumínio trocável & $\mathrm{cmol} \mathrm{I}^{-1}$ & 2,2 & 3,6 & 4,3 \\
\hline Hidrogênio + Alumínio & $\operatorname{cmllol}_{c} \mathrm{~L}$ & 6,8 & 10,5 & 12,8 \\
\hline $\mathrm{CTC}_{\text {efetiva }}$ & & 3,8 & 4,9 & 5,3 \\
\hline $\mathrm{CTC}_{\mathrm{pH} 7}$ & & 8,4 & 11,8 & 13,8 \\
\hline Saturação por bases (V) & $0 \%$ & 20 & 11 & 7 \\
\hline Saturação por Alumínio (m) & $\%$ & 57 & 73 & 82 \\
\hline Cobre & & 1,4 & 1,5 & 1,6 \\
\hline Zinco & $\operatorname{mo~} \mathrm{kg}^{-1}$ & 0,8 & 0,7 & 0,3 \\
\hline Ferro & ing Kg & 346 & 356 & 227 \\
\hline Manganês & & 11,6 & 4,4 & 2,0 \\
\hline Carbono orgânico & $\mathrm{g} \mathrm{kg}^{-1}$ & 12,71 & 12,32 & 8,23 \\
\hline
\end{tabular}

A análise da densidade do solo foi realizada conforme o método do anel volumétrico de Kopecky (KIEHL, 1979). Os macro e micronutrientes, bem como o carbono orgânico do solo, foram determinados, segundo a metodologia proposta por Tedesco et al. (1995) e Miyazawa et al. (1999).

Os solos da região em estudo, conforme EMBRAPA (1973), pertencem à Unidade de Mapeamento São Jerônimo. De acordo com EMBRAPA (1999), o solo da região é caracterizado como Argissolo Vermelho Alítico típico, textura média/argilosa, relevo ondulado e substrato granito.

O trabalho foi realizado no mês de março de 2001, em um povoamento instalado em 1993, com densidade inicial de 1.960 plantas por ha $(3,0$ $\mathrm{m}$ entre linhas e 1,7 $\mathrm{m}$ entre plantas).

Inicialmente, em uma área com condições de sítio semelhante, foram demarcadas 7 parcelas de $18 \mathrm{~m}$ x $24 \mathrm{~m}$, nas quais foi realizado o inventário florestal, medindo o DAP (diâmetro à altura do peito) de todas as árvores da parcela e altura de $20 \%$ delas. Na medição do DAP, foi utilizada fita métrica e na determinação da altura das árvores foi utilizado hipsômetro Vertex. Com base nos dados do inventário florestal, os diâmetros foram agrupados em classes, de maneira a abranger todas as variações do povoamento. O número de classes $(\mathrm{K})$ foi obtido mediante cálculos matemáticos pelo modelo: $K=1+3,3^{*} \log n$ em que: $n=$ número de elementos da amostra e o intervalo de classes (h): $h=H / K$, em que: $\mathrm{H}=$ amplitude total $\left(\mathrm{DAP}_{\text {máximo }}-\mathrm{DAP}_{\text {mínimo }}\right)$. Para estimar a altura das árvores que não foram medidas no campo, utilizou-se o modelo de relação hipsométrica: $\mathrm{h}=\mathrm{b}_{0}+\mathrm{b}_{1} /$

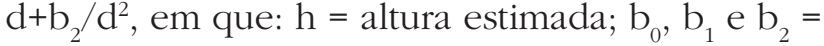
coeficientes da equação; $\mathrm{d}=$ diâmetro a altura do peito. Na determinação da biomassa acima do solo, 
foram abatidas 21 árvores no povoamento, sendo escolhidas três árvores dentro de cada classe de diâmetro anteriormente determinada $(5,1-8,0 ; 8,1$ 11,$0 ; 11,1-14,0 ; 14,1-17,0 ; 17,1-20,0 ; 20,1-23,0$ e $23,1-$ $26,0)$, sendo a primeira com o DAP igual ao centro de classe, a segunda com o DAP $1,0 \mathrm{~cm}$ menor que o DAP do centro de classe e a terceira com o DAP $1,0 \mathrm{~cm}$ maior que o DAP do centro da classe. As 21 árvores abatidas tinham DAP de 5,5; 6,5; 7,5; 8,$5 ; 9,5 ; 10,5 ; 11,5 ; 12,5 ; 13,5 ; 14,5 ; 15,5 ; 16,5 ; 17,5$; 18,$5 ; 19,5 ; 20,5 ; 21,5 ; 22,5 ; 23,5 ; 24,5$ e $25,5 \mathrm{~cm}$.

Inicialmente escolheu-se a árvore com o DAP desejado, logo após, essa foi cortada rente ao solo, avaliando-se os seguintes componentes: folhas, galhos vivos, galhos mortos, casca do tronco e madeira do tronco. Imediatamente após o corte, foi coletada uma amostra de folhas do terço médio da copa nos quatro pontos cardeais para determinar o fator de umidade e análise química. Após isso, as árvores foram seccionadas e divididas em galhos, classificados em vivos (verdes) e mortos (secos), madeira e casca. Dos galhos vivos, foram separadas todas as folhas.

Todo o material morto foi pesado a campo com balança de gancho com precisão de $100 \mathrm{~g}$ e as amostras foram pesadas com balança digital com precisão de 1,0 g. Logo, as amostras eram devidamente identificadas e enviadas para análises ao Laboratório de Ecologia Florestal do Departamento de Ciências Florestais da Universidade Federal de Santa Maria. No Laboratório as amostras foram armazenadas em estufa com circulação e renovação de ar a $75^{\circ} \mathrm{C}$, por um período de 72 horas, sendo resfriado em dessecadores e pesado em balança com 0,01 g de precisão. Após, esse material foi moído em moinho tipo Wiley com mesch 30 .

Na determinação da biomassa abaixo do solo, demarcou-se a área útil de cada planta $(1,7$ $\mathrm{m} \times 3,0 \mathrm{~m}=5,1 \mathrm{~m}^{2}$ ), escavando-se até $60 \mathrm{~cm}$ de profundidade. As raízes foram separadas desse volume de solo, retirando-se uma amostra para determinação do fator de umidade e para posterior análise química. As raízes foram amostradas e pesadas a campo, sendo utilizada uma balança com precisão de 1,0 g para as amostras e uma balança de gancho, com precisão de 100 g, para as massas totais. Essas amostras também foram enviadas ao
Laboratório de Ecologia Florestal para secagem, determinação de peso seco e moagem do material.

As coletas de serapilheira acumulada foram realizadas com o auxílio de uma moldura de ferro com dimensões de $25 \mathrm{~cm}$ x $25 \mathrm{~cm}$, em um número de 6 amostras por parcela, sendo 3 amostras na linha de cultivo e 3 amostras na entrelinha, totalizando 42 amostras na área estudada. Todo o material encontrado no interior do coletor foi devidamente recolhido, acondicionado em sacos de papel e levado ao Laboratório de Ecologia Florestal. No laboratório, o material foi posto para secar em estufa com circulação e renovação de ar, a uma temperatura de $75^{\circ} \mathrm{C}$ por um período de 72 horas. Após seco, o material foi resfriado em dessecadores e pesado em balança com 0,01 g de precisão. Logo após, essas amostras foram enviadas ao Laboratório de Ecologia Florestal para secagem, determinação de peso seco e moagem do material.

As análises químicas de tecido vegetal de $\mathrm{N}, \mathrm{P}, \mathrm{S}, \mathrm{K}, \mathrm{Ca}$ e Mg foram determinadas por digestão úmida. As análises de $\mathrm{N}$ foram feitas por titulação. O N foi determinado pelo método Kjeldahl, chamado também de digestão sulfúrica, usando o destilador de nitrogênio. As amostras de $\mathrm{K}$ foram lidas no fotômetro de chama e as amostras de P e $S$ foram lidas no espectrofotômetro UV-VIS. No espectrofotômetro de absorção atômica (EAA) foram lidas as amostras de Ca e Mg (TEDESCO et al., 1995; MIYAZAWA et al., 1999).

\section{Resultados e discussão}

\section{Biomassa}

A produção de biomassa pelos órgãos da planta seguiu a seguinte ordem: madeira $>$ raízes $>$ galhos vivos $>$ casca $>$ galhos mortos $>$ folhas (QUADRO 2). Nesse povoamento, a biomassa do componente folha é menor que os demais, pois esse dado é diferente de uma floresta em idade juvenil, onde Caldeira (1998), trabalhando em um povoamento de Acácia-negra, procedências Batemans Bay e Bodalla, aos 2,4 anos de idade, encontrou a seguinte ordem: madeira $>$ folhas $>$ galhos vivos $>$ casca $>$ galhos mortos. 
QUADRO 2 - Biomassa média e percentual dos componentes das árvores de um povoamento de Acacia mearnsii

Chart 2 - Biomass average and percentage of tree components in an Acacia mearnsii stand

\begin{tabular}{|lcc|}
\hline Componente & Biomassa $\left(\mathbf{M g ~ h a} \mathbf{~}^{-\mathbf{1}}\right)$ & Percentagem \\
\hline Folhas & 3,92 & 2,97 \\
Galhos Mortos & 6,07 & 4,59 \\
Galhos Vivos & 12,37 & 9,37 \\
Casca & 10,93 & 8,28 \\
Madeira & 82,35 & 62,34 \\
(total acima do solo) & 115,64 & 87,55 \\
Raízes & 16,46 & 12,45 \\
\hline Total & $\mathbf{1 3 2 , 1 0}$ & $\mathbf{1 0 0 , 0 0}$ \\
\hline
\end{tabular}

Fonte: BARICHELLO et al., (2004)

A biomassa acima do solo representou $87,5 \%$ da biomassa total das árvores do povoamento, sendo que o fuste (madeira + casca) e a copa (folhas, galhos vivos e galhos mortos) representaram, respectivamente, 70,6 e $16,9 \%$ da biomassa total do povoamento.

\section{Macronutrientes}

Foi observado que as maiores concentrações de macronutrientes no povoamento de Acácia-negra localizavam-se nas folhas, enquanto que as menores foram observadas na madeira, exceto o fósforo e potássio, pois sua menor concentração foi encontrada nas raízes (QUADRO 3). O teor de $\mathrm{N}$ nos componentes folhas e casca foi semelhante ao encontrado por Calil (2003) e superior nos demais componentes. No entanto, o teor de $\mathrm{N}$ foi superior em todos os componentes encontrados por Neves (2000), trabalhando em plantio de eucalipto.

$O$ alto teor de nitrogênio encontrado nas folhas de Acácia-negra pode ser justificado pela capacidade que a espécie possui de fixar $\mathrm{N}_{2}$ da atmosfera por meio de bactérias do gênero Rhizobium (FRANCO, et al. 1994). O teor observado neste trabalho está acima dos valores considerados adequados para o Eucalyptus (BELLOTE; SILVA, 2000).

QUADRO 3 - Teor médio de macronutrientes nos componentes de biomassa de Acacia mearnsi. Chart 3 - Average macronutrients content in biomass components of Acacia mearnsii.

\begin{tabular}{|lcccccc|}
\hline & $\mathbf{N}$ & $\mathbf{P}$ & $\mathbf{K}$ & $\mathbf{C a}$ & $\mathbf{M g}$ & $\mathbf{S}$ \\
\cline { 2 - 7 } Componente & & \multicolumn{7}{c|}{$\mathbf{g ~ k g}^{-\mathbf{1}}$} \\
\hline Folhas & 30,13 & 1,24 & 9,59 & 11,29 & 2,54 & 1,71 \\
Galhos Mortos & 7,88 & 0,15 & 2,60 & 5,74 & 1,28 & 0,40 \\
Galhos Vivos & 8,45 & 0,38 & 7,43 & 6,73 & 1,31 & 0,43 \\
Casca & 10,32 & 0,24 & 5,90 & 10,33 & 1,39 & 0,49 \\
Madeira & 2,10 & 0,08 & 1,33 & 1,56 & 0,49 & 0,24 \\
Raízes & 4,38 & 0,07 & 1,31 & 4,42 & 0,51 & 0,33 \\
\hline
\end{tabular}


As maiores concentrações de magnésio foram encontradas nas folhas. Esse elemento, segundo Kozlowski e Pallardy (1996), faz parte do componente fotossintético, ou seja, faz parte da estrutura da clorofila a e b, sendo comum sua maior concentração nas folhas do que em outros componentes das plantas.

O elevado teor de macronutrientes nas folhas, em relação a outros componentes das árvores, torna a folha muito importante na ciclagem de nutrientes, embora apresente um menor percentual em relação à biomassa total das árvores. De acordo com Kozlowski e Pallar- dy (1996), os componentes folhas possuem a maioria das células vivas, tendendo a acumular maiores quantidades de nutrientes em razão dos processos de transpiração e fotossíntese.

O carbono orgânico variou entre 40,4\% e $43,3 \%$, sendo que o maior teor foi encontrado nas folhas (QUADRO 4). De um modo geral, os componentes da copa (folhas e galhos) e casca decompõem-se mais rápido, enquanto o tronco e raízes têm uma taxa de decomposição mais lenta, uma vez os primeiros possuem menor relação C/ N (QUADRO 5).

QUADRO 4 - Teor médio e conteúdo de carbono orgânico nos componentes de biomassa e serapilheira de Acacia mearnsii.

Chart 4 - Average contents and amount of organic carbon in biomass and litter of Acacia mearnsii.

\begin{tabular}{|lcc|}
\hline & Teor & Conteúdo \\
\cline { 2 - 3 } Componentes & $\mathbf{g ~ k g ~}^{\mathbf{- 1}}$ & $\mathbf{~ k g ~ h a}^{-\mathbf{1}}$ \\
\cline { 2 - 3 } & 433,5 & $1.662,00$ \\
Folhas & 410,1 & $2.483,05$ \\
Galhos Mortos & 404,5 & $4.916,40$ \\
Casca & 407,0 & $4.448,19$ \\
Madeira & 416,9 & $34.365,56$ \\
Raízes & 416,4 & $6.736,41$ \\
\hline Total & - & $\mathbf{5 4 . 6 1 1 , 6 1}$ \\
\hline Serapilheira & $\mathbf{3 4 5 , \mathbf { 1 }}$ & $\mathbf{8 . 8 7 9 , 4 7}$ \\
\hline
\end{tabular}

QUADRO 5 - Relação C/N dos diferentes componentes da biomassa de Acacia mearnsii. Chart 5 - Relation $C / N$ of the different biomass components of Acacia mearnsii.

\begin{tabular}{|lc|}
\hline Componente & Relação C/N \\
\hline Folhas & 14,39 \\
Galhos Mortos & 52,04 \\
Galhos Vivos & 47,87 \\
Casca & 39,44 \\
Madeira & 198,52 \\
Raízes & 95,07 \\
\hline
\end{tabular}




\section{Conteúdo de macronutrientes}

O conteúdo de nutrientes em um povoamento florestal é conseqüência da concentração e da produção de biomassa nos diferentes componentes das árvores e da idade das árvores. Nesse sentido, num povoamento de Acácia-negra aos 2,4 anos de idade, Caldeira et al. (2000) encontraram a maior quantidade de todos os macronutrientes nas folhas e a menor quantidade nos galhos mortos.
No presente estudo, constatou-se que a madeira é o componente que possui a maior quantidade de macronutrientes, com exceção do Ca, em função de ocupar $62,34 \%$ da biomassa da planta. Nos galhos mortos ocorre o menor acúmulo de nutrientes (QUADRO 6). Essa distribuição de nutrientes está relacionada à idade das árvores, que é de 8 anos.

QUADRO 6 - Conteúdo de macronutrientes nos componentes de biomassa de Acácia mearnsii. Chart 6 - Macronutrients content in biomass components of Acacia mearnsii.

\begin{tabular}{|lcrrrrr|}
\hline \multirow{2}{*}{ Componente } & $\mathbf{N}$ & $\mathbf{P}$ & $\mathbf{K}$ & $\mathbf{C a}$ & $\mathbf{M g}$ & $\mathbf{S}$ \\
\cline { 2 - 7 } & \multicolumn{7}{c|}{$\mathbf{k g ~ h a}^{-\mathbf{1}}$} \\
\hline Folhas & 117,75 & 4,82 & 37,59 & 45,29 & 9,76 & 5,72 \\
Galhos Mortos & 41,95 & 0,70 & 15,78 & 31,92 & 7,08 & 2,89 \\
Galhos Vivos & 95,71 & 3,93 & 91,91 & 82,94 & 14,59 & 5,07 \\
Casca & 105,81 & 2,42 & 64,49 & 115,68 & 12,88 & 5,43 \\
Madeira & 153,69 & 5,45 & 109,52 & 110,70 & 37,07 & 17,04 \\
Raízes & 68,28 & 1,28 & 21,56 & 72,22 & 8,00 & 6,18 \\
Total & 583,19 & 18,59 & 340,85 & 458,75 & 89,39 & 42,32 \\
Percentagem do Total & 38,0 & 1,2 & 22,2 & 30,0 & 5,8 & 2,8 \\
& & & & & & \\
\end{tabular}

\section{Serapilheira}

No povoamento de Acácia-negra com 8 anos de idade, encontraram-se $25,73 \mathrm{mg} \mathrm{ha}^{-1}$ de biomassa seca de serapilheira acumulada sobre a superfície do solo. Os teores e o conteúdo de macronutrientes na serapilheira são apresentados no Quadro 7. Os teores dos macronutrientes seguiram a ordem: $\mathrm{N}>\mathrm{K}>\mathrm{Ca}>$ $\mathrm{Mg}>\mathrm{P}>\mathrm{S}$. Caldeira et al. (1999), trabalhando com folhedo de Acácia-negra aos 9 anos de idade, e Calil (2003), trabalhando com serapilheira, encontraram a seguinte ordem: $\mathrm{N}>$ $\mathrm{Ca}>\mathrm{K}>\mathrm{Mg}>\mathrm{P}$.

QUADRO 7 - Teor e conteúdo de macronutrientes na serapilheira de um povoamento de Acacia mearnsii.

Chart 7 - Average content and amount of macronutrients in litter from an Acacia mearnsii stand.

\begin{tabular}{|c|c|c|c|c|c|c|}
\hline \multirow{3}{*}{ Teor } & $\mathbf{N}$ & $\mathbf{P}$ & $\mathbf{K}$ & $\mathbf{C a}$ & Mg & $\mathbf{S}$ \\
\hline & \multicolumn{6}{|c|}{$\mathrm{g} \mathrm{kg}^{-1}$} \\
\hline & 18,38 & 0,59 & 12,92 & 10,48 & 1,27 & 0,40 \\
\hline Conteúdo & \multicolumn{6}{|c|}{ kg ha ${ }^{-1}$} \\
\hline total & 472,95 & 15,18 & 332,52 & 269,78 & 32,60 & 10,21 \\
\hline
\end{tabular}


Do total de $1,13 \mathrm{mg} \mathrm{ha}^{-1}$ de macronutrientes na serapilheira, $41,7 \%$ é de N; $1,3 \%$ é de P; 29,3\% é de K; $23,8 \%$ é de Ca; $2,9 \%$ é de Mg e 1,0\% é de $\mathrm{S}$.

O conteúdo de fósforo na serapilheira foi muito semelhante àquele encontrado na biomassa arbórea. Isso sugere que a presença da serapilheira é de fundamental importância na manutenção da capacidade produtiva dos sítios onde se encontra a Acácia-negra, devido à importância da ciclagem geoquímica para a absorção desse elemento pelas plantas (CALDEIRA et al., 1999).

\section{Conclusões}

A biomassa total produzida (acima do solo + abaixo do solo $=132,1 \mathrm{mg} \mathrm{ha}^{-1}$ ) acumulou 54,61 mg ha ${ }^{-1}$ de carbono orgânico.

O conteúdo de macronutrientes na biomassa total teve a seguinte ordem decrescente: $\mathrm{N}$ $>\mathrm{Ca}>\mathrm{K}>\mathrm{Mg}>\mathrm{S}>\mathrm{P}$.

A biomassa de serapilheira $\left(25,73 \mathrm{mg} \mathrm{ha}^{-}\right.$

$\left.{ }^{1}\right)$ acumulou um total de $8,88 \mathrm{mg} \mathrm{ha}^{-1}$ de carbono orgânico e o conteúdo de macronutrientes possui a seguinte ordem decrescente: $\mathrm{N}>\mathrm{K}>\mathrm{Ca}>\mathrm{Mg}>$ $\mathrm{P}>\mathrm{S}$.

\section{Referências}

AUER, C. G.; SILVA, R. Fixação de nitrogênio em espécies arbóreas. In: CARDOSO, E. J. B. N.; TSAI, S. M.; NEVES, M. C. P. Microbiologia do solo. Campinas: Sociedade Brasileira de Ciência do Solo, 1992. p. 157-172.

BARICHELLO, L. R.; SCHUMACHER, M. V.; CALDEIRA, M. V. W. Quantificação da biomassa em floresta de Acacia mearnsii De Wild. na região sul do Brasil. In: CONGRESSO INTERNACIONAL DE BIOENERGIA 1., Campo Grande, 2004. Anais... Viçosa: Renabio, 2004.

BELlOTE, A. F. J.; SILVA, H. D. Técnicas de amostragem e avaliações nutricionais em plantios de Eucalyptus spp. In: GONÇALVES, J. L. de M.; BENEDETTI, V. Nutrição e fertilização florestal. Piracicaba: Instituto de Pesquisas e Estudos Florestais, 2000. p.105133.

CALDEIRA, M. V. W. Quantificação da biomassa e do conteúdo de nutrientes em diferentes precedências de Acácia-negra (Acacia mearsnsii De Wild.). 1998. 96 f. Dissertação (Mestrado) - Universidade Federal de Santa Maria, Santa Maria, 1998.

CALDEIRA, M. V. W., et al. dos. Concentração e redistribuição de nutrientes nas folhas e no folhedo em um povoamentno de Acacia mearnsii De Wild. no Rio Grande do Sul. Ciência Florestal, Santa Maria, v. 9, n. 1, p. 1924, 1999.

CALDEIRA, M. V. W., et al. Ciclagem de nutrientes em Acacia mearnsii De Wild. V. Quantificação do conteúdo de nutrientes na biomassa aérea de Acacia mearnsii De Wild. procedência Australiana. Ciência Rural, Santa Maria, v. 30, n. 6, p. 977-982, 2000.

CALIL, F. N. Aspectos da ciclagem de nutrientes em um sistema silvopastoril na região de Tupanciretã. Relatório. Santa Maria: UFSM, 2003. Relatório técnico.

EMPRESA BRASILEIRA DE PESQUISA AGROPECUARIA. Levantamento de reconhecimento dos solos do Estado do Rio Grande do Sul. Recife, 1973. (Boletim Técnico, 30).

EMPRESA BRASILEIRA DE PESQUISA AGROPECUARIA. SNPS Sistema brasileiro de classificação e levantamento de solos. Rio de Janeiro, RJ: EMBRAPA,1999.

FRANCO, A. A., et al. Revegetação de áreas de mineração de bauxita em Porto Trombetas-PA com leguminosas arbóreas noduladas e micorrizadas. In: SIMPOSIO SUL-AMERICANO, 1.; SIMPOSIO NACIONAL DE RECUPARAÇÃO DE ÁREAS DEGRADADAS, 2., Foz do Iguaçu, 1994. Anais... Curitiba: FUPEF, p. 145-153. 1994. 
FREITAS, R. A. Estudo de biomassa e do conteúdo de nutrientes em um povoamento de Eucalyptus grandis Hill ex Maiden plantado em solo sujeito a arenização no município de Alegrete-RS. 2000. 60 f. Dissertação (Mestrado em Engenharia Florestal) - Universidade Federal de Santa Maria, Santa Maria, 2000.

HAAG, H. P. Ciclagem de nutrientes em florestas tropicais. Campinas, SP. Brasil, 1985.

INSTITUTO DE PESQUISAS AGRONÔMICAS. Seção de Ecologia Agrícola. Atlas agroclimático do Estado do Rio Grande do Sul. Porto Alegre, v. 3, 1989.

KANNEGIESSER, U. Apuntes sobre algunas acacias australianas. 1.- Acacia mearnsii De Willd. Ciencia e Investigación Forestal, v. 4, n. 2, p. 198-202, 1990.

KIEHL, E. J. Manual de edafologia. São Paulo, SP: Ceres, 1979. p. 262.

KOZLOWSKI, T. T.; PALLARDY, S. G. Physiological of woody. 2. ed. San Diego: Academic, 1996.

LARCHER, W. Ecofisiologia vegetal. São Paulo, SP: EPU, 1986.

MIYAZAWA, M., et al. Análises químicas de tecido vegetal. In: SILVA, F. C. Manual de análises químicas de solos, plantas e fertilizantes. Brasília: Embrapa, 1999. p. 171223. (Comunicação para Transferência e Tecnologia).
MORENO, J.A. Clima do Rio Grande do Sul. Porto Alegre: Secretaria da Agricultura, 1961.

NEVES, J. C. L. Produção e participação de biomassa, aspectos nutricionais e hídricos em plantios clonais de eucalipto na região litorânea do Espírito Santo. 2000. 191 f. Tese (Doutorado em Produção Vegetal) Universidade Estadual do Norte Fluminense, Rio de Janeiro, 2000.

SCHUMACHER, M. V. Aspectos da ciclagem de nutrientes e do microclima em talhões de Eucalyptus camaldulensis Dehnh., Eucalyptus grandis W. Hill ex Maiden e Eucalyptus torelliana F. Muell. 1992. $87 \mathrm{f}$. Dissertação (Mestrado em Ciência Florestal) Escola Superior de Agricultura "Luiz de Queiroz" - Universidade de São Paulo, Piracicaba, 1992.

SCHUMACHER, M. V. Naehrstoffkreislauf in verschiedenen Bestaenden von Eucalyptus saligna (Smith), Eucalyptus dunnii (Maiden) und Eucalyptus globulus (Labillardière) in Rio Grande do Sul, Brasilien. 1995. 167 f. Tese (Doutorado) - Viena: Áustria, 1995.

SHERRY, S. P. The black wattle (Acacia mearnsii). Pietermaritzburg: University of Natal, 1971.

TEDESCO, M. J., et al. Análises de solos, plantas e outros materiais. 2. ed. Porto Alegre: UFRGS, 1995. (Boletim Técnico, 5).

Recebido: 02/06/2005 Aprovado: 30/09/2005 